\title{
A robotic irrigation system for urban gardening and agriculture
}

\author{
Ioannis Gravalos, Avgoustinos Avgousti, Theodoros Gialamas, Nikolaos Alfieris, Georgios Paschalidis
}

School of Agricultural Sciences, University of Thessaly, Larissa, Greece

\begin{abstract}
Water supply limits and continued population growth have intensified the search for measures to conserve water in urban gardening and agriculture. The efficiency of water use is depended on performance of the irrigation technologies and management practices. In this study, a robotic irrigation system was developed that consists of a moving bridge manipulator and a sensor-based platform. The manipulator constructed is partly using open-source components and software, and is easily reconfigurable and extendable. In combination to the sensor-based platform this custommade manipulator has the potential to monitor the soil water content (SWC) in real time. The irrigation robotic system was tested in an experimental soil tank. The total surface of the soil tank was divided by a raster into 18 equal quadrants. The water management for maintaining water content in the soil tank within tolerable lower limit (refill point) was based on three irrigation treatments: i) quadrants whose SWC is below the refill point are irrigated; ii) quadrants are irrigated only when the daily mean SWC of the tank is below the refill point and only for those whose actual SWC is lower than that limit; and iii) quadrants are irrigated every two days with constant amount of water. A comparison of the results of the three irrigation treatments showed that the second treatment gave less irrigation events and less applied water. Finally, we could conclude that the performance of the fabricated robotic system is appropriate and it could play an important role in achieving sustainable irrigation into urban food systems.
\end{abstract}

Correspondence: Ioannis Gravalos, School of Agricultural Sciences, University of Thessaly, Periferiaki Larissas-Trikalon, 41500 Larissa, Greece.

Tel./Fax: +302410.684216.

E-mail: gravalos@teilar.gr

Key words: Farming automation; intelligent irrigation; soil moisture sensor; single-board microcontroller.

Received for publication: 9 April 2019.

Accepted for publication: 28 August 2019.

CCopyright: the Author(s), 2019

Licensee PAGEPress, Italy

Journal of Agricultural Engineering 2019; L:966

doi:10.4081/jae.2019.966

This article is distributed under the terms of the Creative Commons Attribution Noncommercial License (by-nc 4.0) which permits any noncommercial use, distribution, and reproduction in any medium, provided the original author(s) and source are credited.

\section{Introduction}

Urban gardening and agriculture are the practice of cultivating crops in densely populated areas such as city open spaces (Ernwein, 2014). These gardens produce fresh vegetables and fruits for daily consumption. In the USA and EU, urban gardening and agriculture has become increasingly popular and is referred to in a variety of ways, e.g., allotment gardening, leisure gardening, urban homesteading, edible landscaping (Sidblad, 2000; Opitz et al., 2016). Urban and peri-urban agriculture in developing countries represents an opportunity for improving food supply, living standards, and local economy (Orsini et al., 2013).

Urban gardening and agriculture have an important role in enhancing food production, but with significant costs and constrains. It utilises significant amount of municipal water for crops growing (Dhakal et al., 2015). Moreover, municipal water supplies are typically much more expensive than agricultural water supplies and also may be more energy-intensive, as municipal water has been treated to drinking water standards (Nolasco, 2011). Thus, efficient use of municipal water supplies in urban gardening and agriculture is a priority target.

Irrigation in urban gardening and agriculture is performed by the gardeners with traditional techniques (Cofie and Veenhuizen, 2008). Most gardeners manage the irrigation water uniformly, despite spatial and temporal variability in soil water content (SWC). The computerised control may be taken as a good alternative for controlling urban gardening and agriculture irrigation systems. Today, several irrigation control systems are commercially available with many different features (Gravalos et al., 2007). These control systems activate irrigation only when soil water is below a certain threshold. However, computerised control made it possible to analyse and map spatial soil water data using statistical approaches and geographic information systems (Gravalos et al., 2013). In succinct terms, precision involves putting the irrigation water at the right rate, in the right place at the right time (Kohanbash et al., 2011). The benefits of precision irrigation in urban gardening and agriculture include more efficient management of municipal water, improved crop yield and environmental sustainability.

Unified robotic systems can offer great benefits for saving irrigation water. It is the kind of technology that aims to optimise irrigation water management and focus on optimal yield. For example, in the work of Goldberg (2000) an in industrial manipulator (telegarden) is presented that is mounted on the centre of a circular pot filled with soil. The manipulator is equipped with an irrigation hose. Users can irrigate plants from a distance via internet. In the work of Correll et al. (2009) a gardening robotic manipulator is presented able to locate plants and water them. Similarly, in the work of Aronson (2014) a gantry robotic system is presented that can cultivate different crops. It can perform all growing operations such as weed control, irrigation, etc. More recently, in the work of Agostini et al. (2017) a cognitive system is proposed that integrates a robotic platform with artificial intelligence techniques 
that decides the amount of irrigation water needs for each plant according to its history. It is obvious that autonomous robots can take care of crops on small patches of land to improve plants yield while saving irrigation water, nutrients and overall energy consumption.

This contribution presents a robotic irrigation system that can be used in urban gardening and agriculture. The investigation is related to how the robotic system: i) can sense SWC in a wood soil tank; and ii) can automatically supply each quadrant of the soil tank with specified amount of water. Moreover, the development of the prototype robotic system will be based on the following specifications: flexible and easily operable.

\section{Robotic system architecture}

As illustrated in Figure 1, the overall robotic system architecture is composed of two units: i) a sensor-based platform; and ii) a manipulator working in the Cartesian coordinate system known as a moving bridge.

\section{Sensor-based platform}

The sensor-based platform travels through the access tubes that were placed along the soil tank, under the soil surface, and monitors the SWC in real time. This is the same prototype sensor-based platform developed by Gravalos et al. (2012; 2017). A similar mobile dielectric volumetric soil water content sensor has also been developed by Sun et al. (2014). The sensor-based platform can be classified as a wall-press type robotic system. It was composed of a modified commercial soil water sensor and a mobile platform. The mobile platform consists of two articulated wheeled bases that are linked via universal joints. The body of the wheeled bases is circular in shape, and is adequate to support the driving and sliding wheels. The driving wheels are supported via bumper suspensions. The suspension system allows motion only along the vertical direction and relies its function on flexible members (compression springs), to hold the bumper loosely in place. The deflection of the bumper suspension gives foldable characteristics to the driving wheels, which maintain steady contact with the access tube walls. Two motors are engaged in platform movement. These are high quality DC motors that are installed close to the driving wheel parts. Each wheel module uses elastic rings with a high friction coefficient. In this way, the mobile platform is able to hold onto the surface of the access tube firmly and move smoothly. The electronic control module of the sensor-based platform is installed in the ground station. It contains all the drivers necessary to drive the motors and allows the motor speed to be controlled in both the forward and reverse directions. The length of the sensor-based platform is $235 \mathrm{~mm}$ and the outer diameter can be varied from $48 \mathrm{~mm}$ up to $54 \mathrm{~mm}$.

The commercially available capacitance sensor Diviner 2000 has been used on the mobile platform. This capacitance sensor was selected due to its good mobility within the access tubes. The manufacturer reports that the resolution of the sensor is $10 \mathrm{~cm}$, while the radial sensitivity is $5-10 \mathrm{~cm}$ from the outer wall of the access tube (Sentek Pty Ltd., 2007). It is a cylindrical ring capacitance probe that operates in excess of $100 \mathrm{MHz}$. The frequencies in air, water and soil are passed through a normalisation equation to determine a scaled frequency (SF). Calibration of the Diviner 2000 sensor was done under laboratory conditions. The calibration equation was derived from regression analysis of sensor measurements of SF against the SWC $\theta$, according to Groves and Rose (2004).

The sensor-based platform measures the SWC at fixed positions of the access tube spaced out every $24 \mathrm{~cm}$ of length increment (move-stop-measure case). Thus, for the 3 access tubes a total number of 18 measurements are conducted where every single value is the average value of three readings. The sensor data logger

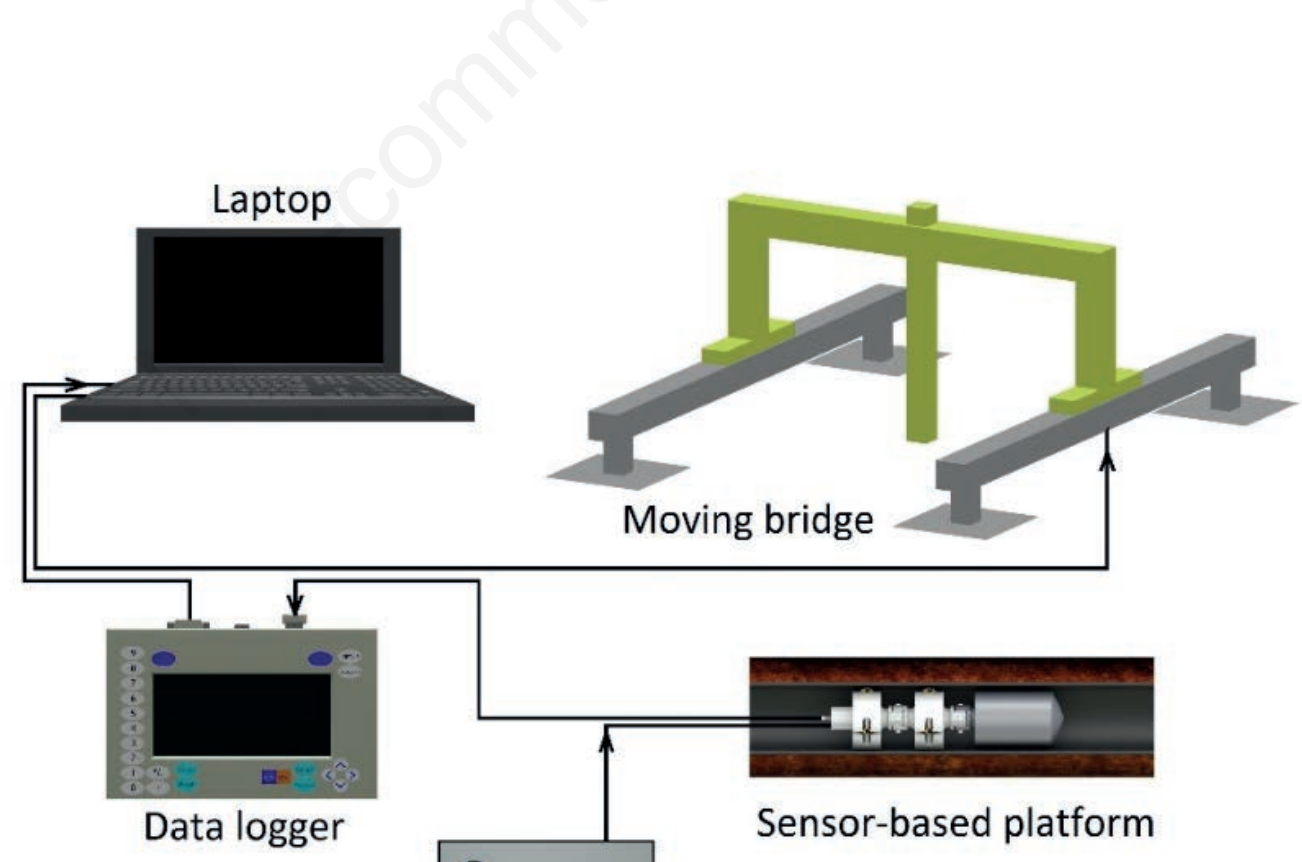

Ground station

Figure 1. Scheme of the robotic system architecture. 
is a data storage, display and conversion device. It is connected to the laptop via a standard serial port. A software application used to download and store data in a backup file or to export backed up data to a comma-separated variables file format. This text-based file format can be viewed and analysed with third party software (such as a Microsoft Excel document).

\section{Moving bridge manipulator}

The Cartesian manipulator developed in this contribution is an example of a moving bridge (Figure 2). It is an electromechanical system with 3 degrees-of-freedom (dof) that travels with a constant velocity and is programmed to automatically apply irrigation water directly onto the surface of the 18 equal rectangular quadrants of the soil tank.

The manipulator comprises three essential components: bridge, carriage, and ram. The bridge moves in the Y-direction along a base frame on the soil tank. The carriage moveable in the $\mathrm{X}$-direction is mounted on the bridge. The ram is mounted on the carriage and moves in the Z-direction. Finally, an irrigation tool is mounted on the end of the ram. The components are made up of different parts such as: linear guide rails, cross-slide lead screws, rods, belts, belt clips, V-wheels, stepper motors, and electronics. The base frame consists of metal brackets and two V-slot linear guide rails so they make a window frame shape. The linear guide rails (black V-slot $20 \times 20 \mathrm{~mm}$ ) are made of light weight material (aluminium). The bridge is movably mounted on the linear guide rails using two $\mathrm{V}$-wheel kits. The carriage includes an aluminium base which is transversely movable on a linear guide rail using a mini V-wheel kit. A shaft coupling is a device used to connect motor shaft to lead screw at their ends for the purpose of transmitting power. A GT2 type of timing belts are used as primary transmissions for the bridge and carriage. Belts are very common transmission parts because their elastic nature enables them to pass over round objects (pulleys) typically with a high degree of efficiency.
The belts are routed correctly around the drive pulleys and around the belt-idler wheels. The GT2 belts positively engage the pulleys, and require only enough tension such that the load acting on the tooth angle does not create a force large enough to pop the tooth out of the pulleys. Small clips are used to attach belts to corners of the linear guide rails (anchored ends). The belts now stay engaged and do not slip when traversing the bridge and carriage on the $\mathrm{Y}$ and $\mathrm{X}$-axis rails.

The manipulator has an electronic control unit (ECU), an emergency button, and several LEDs. The control electronics as well as the programming ones are based on the open-source prototyping platform Arduino. The ECU interprets the G-code streamed from the laptop and provides the correct pulses to the actuators to drive the manipulator according to the program. It is the language used to tell the manipulator where to go in the XYZ-axes areas of travel and what to do when it gets there. The electronics board includes the CNC shield V3.0 and UNO Arduino that can be used in many kinds of robotics and CNC projects. Similarly, to the actuators, the manipulator has three drive motors (stepper motors, model 42BYGHW208 $-2.6 \mathrm{~kg} \cdot \mathrm{cm}$ ), one for each axis of movement. The first stepper motor is mounted on one end of the bridge. The second and third stepper motors are mounted on the carriage and ram, respectively. The stepper motors are controlled by using the A4988 stepper drivers. Each A4988 driver features adjustable current limiting, overcurrent and over temperature protection, and five different micro step resolutions (moving in fixed increments down to 1/16-step). It operates from 8 - $35 \mathrm{~V}$ and can deliver up to approximately 1 A per phase without an additional cooling. 2 pins only (Direction and Step) from microcontroller (Arduino) are used to control the motor movements, one for controlling the rotation direction and another to control the steps.

Grbl Controller is an open source code for controlling the motion of CNC machines (such as the moving bridge manipulator). It is designed for the Arduino to control Grbl shields. Grbl
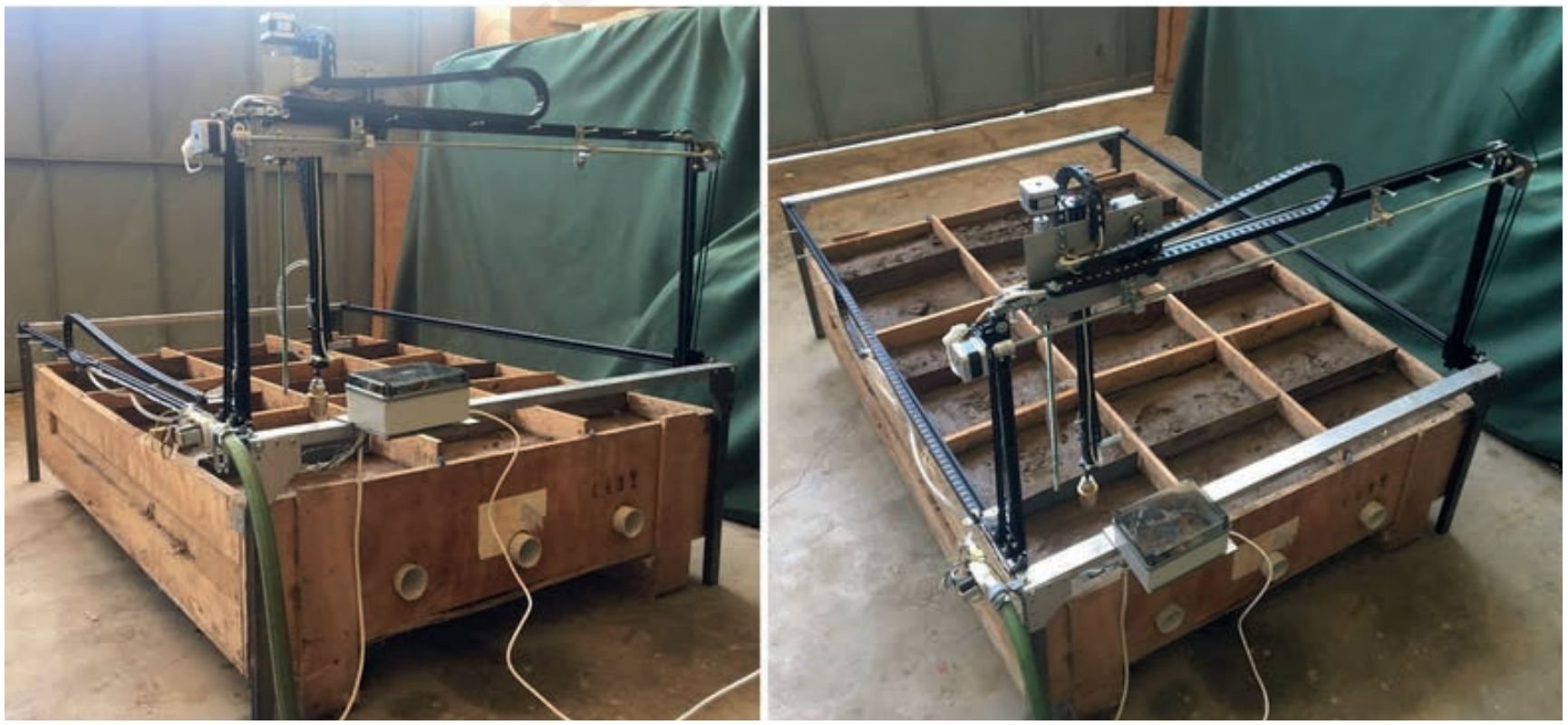

Figure 2. Photographs of the moving bridge manipulator on the soil tank. 
Controller is a user interface that has been designed to allow the gardener to select irrigation tool paths in a simple and intuitive manner. The main window of the user interface controls the setup, loading of a file, jogging, setting offsets for job to be run, etc.

The irrigation system includes a solenoid valve, a one-way valve (check valve), a water flow sensor, and several water hoses. The water solenoid valve is plastic and is similar to those that used for controlling flow to drip irrigation systems. Normally the solenoid valve is closed. When power is applied to the two contacts, the solenoid valve opens and water can push through. It permits flow in only one direction. The solenoid valve has a gasket arrangement inside, so there is a minimum pressure requirement of $0.02 \mathrm{MPa}$. The solenoid water valve operates with anywhere between 6-12 V which is too high to use with the Arduino UNO. To get around this problem a $9 \mathrm{~V}$ power supply was used. The oneway valve is placed vertically on the ram of the moving bridge manipulator and operates as irrigation tool. It is a spring valve with female threaded end used to secure sealing pressure. The water flow sensor is a transducer for flow rate measurement. It is consisting of plastic body, rotor assembly, and hall current sensor. A part of the water flow makes the rotor rotate and the hall-effect sensor detects the rotation of the rotor. The output signal of the sensor is equal to the volume flow rate.

Figure 3 shows the irrigation tool path in the $\mathrm{X}, \mathrm{Y}$ working plane at constant $Z$. The moving bridge transports the irrigation tool to selected positions (points) of the soil tank surface. The irrigation tool covers a planar working area close to $1.6 \mathrm{~m}^{2}$, which is divided by a raster consisting of wood and metal sticks into 18 (3 columns $\times 6$ rows) equal rectangular quadrants. The irrigation tool of mov- ing bridge manipulator can follow a number of different motion trajectories. However, the trajectories followed by irrigation tool are not expected to influence significantly the presented results.

The total irrigation time consists of the motion time that the manipulator reaches goal position at each quadrant and the time of the applying irrigation water (set time). The time it takes the manipulator to release irrigation water are assumed: i) constant in the case study of uniform irrigation; and ii) not constant in the case study of variable rate irrigation. The motion time between two neighbouring goal positions of the same row, as well as the motion time between two neighbouring goal positions of the same column, is assumed constant. Therefore, total time of any irrigation cycle for soil tank is given in the following equation:

$$
t_{i c}=12 t_{r}+10 t_{c}+\sum_{i=1}^{18} t_{w i}
$$

where $t_{i c}$ is the total time of any irrigation cycle (s), $t_{r}$ is the motion time between two neighbouring goal positions of the same row (s), $t_{c}$ is the motion time between two neighbouring goal positions of the same column (s), $t_{w i}$ is the time of the applying irrigation water (s).

The advantage of the moving bridge manipulator is that their totally linear movement allows for simpler control. Because movement can start and stop simultaneously along all three axes, motion of the irrigation tool is smoother. In addition, it has a high degree of rigidity, accuracy, and repeatability.

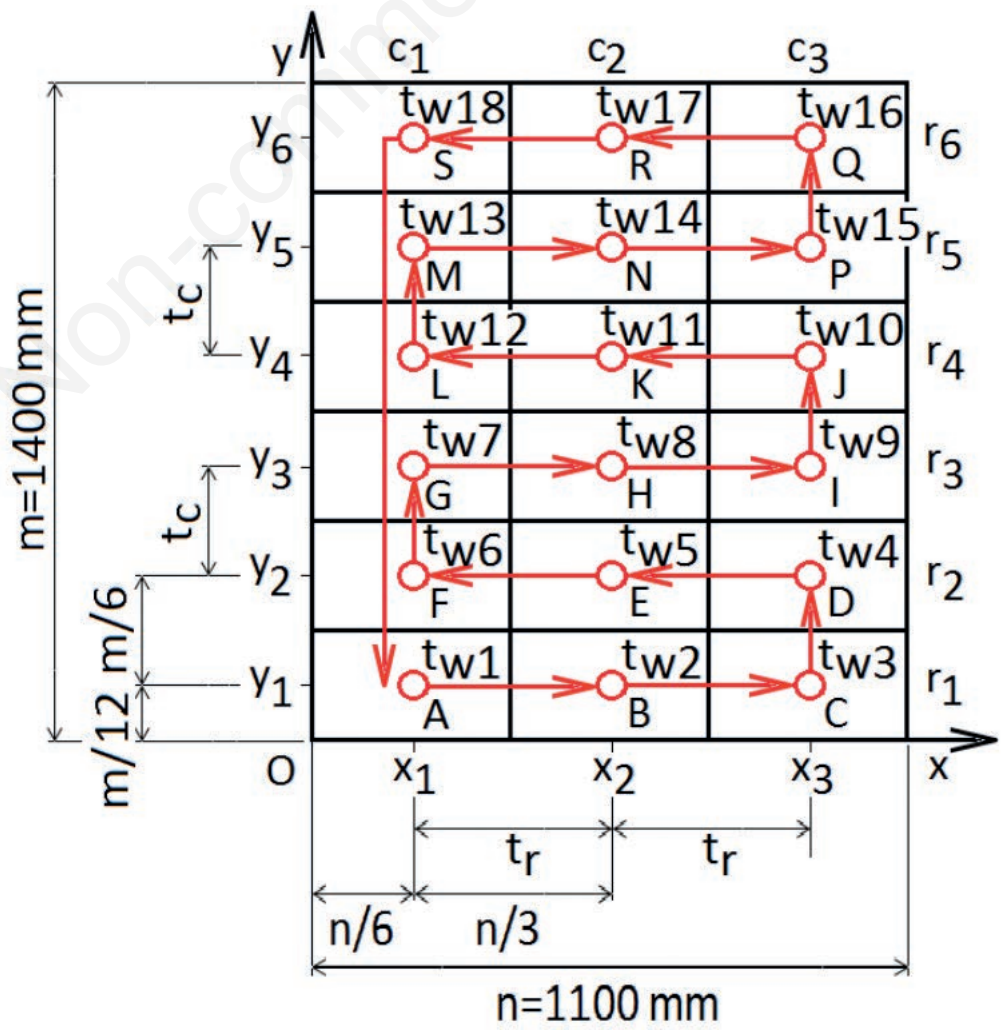

Figure 3. The irrigation tool path in the $X$, $Y$ working plane at constant $Z$. 


\section{Irrigation water management}

The objective of irrigation water management in this contribution is breaking the surface of the experimental soil tank into several rectangular quadrants and treating them independently. By continuous knowledge of SWC, the moving bridge manipulator delivers precise amount of water in the right quadrant of the soil tank. This irrigation practice is used to maintain water content in the soil tank within tolerable lower limit (refill point). Maintaining the SWC about the refill point ensures the plant water demand is met and there are no growth limitations attributed to water availability.

The calculation of the irrigation water depth involves the knowledge of the actual SWC, and the SWC at refill point. The amount of irrigation water needed to bring the soil back to refill point at each quadrant was determined according to Hanks and Ashcroft (1980):

$$
d_{i}=\left(\theta_{r p}-\theta_{a i}\right) \cdot z
$$

where $d_{i}$ is the depth of water applied at each quadrant (m), $\theta_{r p}$ is the SWC at refill point $\left(\mathrm{m}^{3} \cdot \mathrm{m}^{-3}\right), \theta_{a i}$ is the actual SWC at each quadrant $\left(\mathrm{m}^{3} \cdot \mathrm{m}^{-3}\right), z$ is the irrigated soil depth $(\mathrm{m})$.

The proposed water management based on three irrigation treatments:

i) irrigation occurs in quadrants whose SWC is below the refill point and regardless of daily the mean SWC of the soil tank. The equation for this irrigation treatment is given by:

$$
t_{w i}=\left\{\begin{aligned}
\left(d_{i} \cdot A\right) / q, \theta_{a i} & <\theta_{r p} \\
0, \theta_{a i} & \geq \theta_{r p}
\end{aligned}\right.
$$

ii) irrigation occurs only when the daily mean SWC of the soil tank is below the refill point and only in the quadrants with actual SWC lower than that limit. The equation for this irrigation treatment is given by:

$$
t_{w i}=\left\{\begin{array}{c}
\left(d_{i} \cdot A\right) / q, \bar{\theta}_{d}<\theta_{r p} \wedge \theta_{a i}<\theta_{r p} \\
0, \bar{\theta}_{d} \geq \theta_{r p}
\end{array}\right.
$$

where $t_{w i}$ is the time of the applying irrigation water at each quadrant (s), $d_{i}$ is the depth of water applied (m), $A$ is the area irrigated $\left(\mathrm{m}^{2}\right)$, $\mathrm{q}$ is the flow rate $\left(\mathrm{m}^{3} / \mathrm{s}\right)$ of the irrigation system, $\bar{\theta}_{d}$ is the daily mean SWC $\left(\mathrm{m}^{3} \cdot \mathrm{m}^{-3}\right)$ of the soil tank, $\theta_{r p}$ is the SWC at refill point $\left(\mathrm{m}^{3} \cdot \mathrm{m}^{-3}\right), \theta_{a i}$ is the actual SWC at each quadrant $\left(\mathrm{m}^{3} \cdot \mathrm{m}^{-3}\right)$.

iii) irrigation occurs every two days with constant irrigation water supply $(3 \mathrm{~mm})$ and uniformly at all quadrants. This treatment simulates the uniform irrigation of most gardeners. It was used as reference treatment.

The time of the applying irrigation water $t_{w i}$ is used to control the solenoid valve of the irrigation system or the time it takes the manipulator to release irrigation water.

\section{Experimental setup}

Experiments were carried out under laboratory conditions in the School of Agricultural Sciences at the University of Thessaly (Greece). In the laboratory, the ambient temperature was kept approximately constant $\left(\approx 22^{\circ} \mathrm{C}\right)$. The irrigation water treatments were conducted automatically by moving bridge manipulator onto the surface of the experimental soil tank, without crop cover.

A soil tank and rigid polyvinylchloride (PVC) plastic access tubes were used. The soil tank was made of water-resistant wood, $1.40 \mathrm{~m}$ long, $1.10 \mathrm{~m}$ wide, and $0.25 \mathrm{~m}$ deep (total volume $0.4 \mathrm{~m}^{3}$ ). The total surface of the soil tank was divided by a raster consisting of wood and metal sticks into 18 ( 3 columns $\times 6$ rows) equal rectangular quadrants. The raster penetrates soil surface to a depth of $40 \mathrm{~mm}$. The raster was used for trapping the applied water in the individual quadrants and thereby ensuring its distribution. The bottom of the tank was equipped with an artificial layer of gravel used to allow drainage of percolated water. Three PVC pipelines were placed horizontally, along the soil tank, at a depth of $0.15 \mathrm{~m}$ under the soil surface, and at uniform distances. Special attention was paid to the installation of the pipes in the tank, in order to avoid air pockets between the pipes and the soil.

The soil material was passed through two sieves (sized 6.35 and $0.42 \mathrm{~mm}$ ) in order to obtain aggregate mechanical separation and was packed into the soil tank. Soil samples were obtained at predetermined locations in the tank, and were analysed to obtain the soil properties. The field capacity and permanent wilting point of the soil were determined according to Klute (1986) In addition, the refill point was determined according to Taylor and Ashcroft (1972). Soil properties and water retention characteristics are shown in Table 1.

\section{Results and discussion}

The irrigation events and the amount of applied water by the manipulator, the SWC data in each quadrant of the tank, and the time series of daily mean SWC were used to evaluate the irrigation treatments and the fabricated robotic system.

Figure 4 presents a comparison of irrigation events performed by the manipulator during the three different treatments for each quadrant. The manipulator performed most of the irrigation events during the third treatment. A total of 360 events were performed, which were uniformly distributed across all quadrants. During the first treatment, the manipulator carried out a large number of irrigation events in the following quadrants: i) in the B quadrant 60 events; ii) in the P quadrant 60 events as well; iii) in the $\mathrm{M}$ quadrant 48 events; and iv) in the R quadrant 27 events. On the other hand, the irrigation events performed in the other quadrants were limited. Overall, during the first treatment, 222 irrigation events were performed, less than the third treatment. The fewer irrigation events, a total of 87 , were performed by the manipulator during second treatment.

Figure 5 shows the amount of applied water by moving bridge manipulator at each of the 18 quadrants of the soil tank during the

Table 1. Soil properties and water retention characteristics.

\begin{tabular}{llc} 
Properties & & Values \\
\multirow{2}{*}{ Particles size distribution } & Sand & $41 \%$ \\
& Silt & $25 \%$ \\
& Clay & $34 \%$ \\
Bulk density & & $1.33 \mathrm{~g} \mathrm{~cm}^{-3}$ \\
\hline Electrical conductivity & & $0.20 \mathrm{dS} \mathrm{m}^{-1}$ \\
Water retention characteristics & Field capacity & $0.27 \mathrm{~m}^{3} \mathrm{~m}^{-3}$ \\
& Refill point & $0.18 \mathrm{~m}^{3} \mathrm{~m}^{-3}$ \\
& Permanent wilting point & $0.13 \mathrm{~m}^{3} \mathrm{~m}^{-3}$ \\
\hline
\end{tabular}


three different treatments. In the first irrigation treatment, the water was applied by the manipulator in the quadrants whose actual SWC was below the refill point. In the first day of irrigation, the water applied at a high amount of $34 \mathrm{~mm}$ on the tank. During the next days, a small amount of water was applied into more quadrants, except the B quadrant. It should be mentioned that the manipulator applied a total of $38 \mathrm{~mm}$ of water to the B quadrant more than any other. This is due to the fact that the SWC in this quadrant was always measured below the refilling point. Instead, there were also quadrants in which no additional irrigation events were performed outside the first one. Two months later $(01 / 10 / 2016-29 / 11 / 2016)$ variable rate irrigation by manipulator, $88 \mathrm{~mm}$ of water was applied to the area of the soil tank.

In the second treatment, irrigation occurs by the manipulator only when the daily mean SWC of the soil tank is below the refill point and this only in the quadrants with SWC lower than that limit. After 60 days experimental procedure (09/10/201707/12/2017) with the above irrigation constraints, $71 \mathrm{~mm}$ of water applied to the total area of the soil tank. In the first day, the amount of water applied was high and almost uniform in all the quadrants.

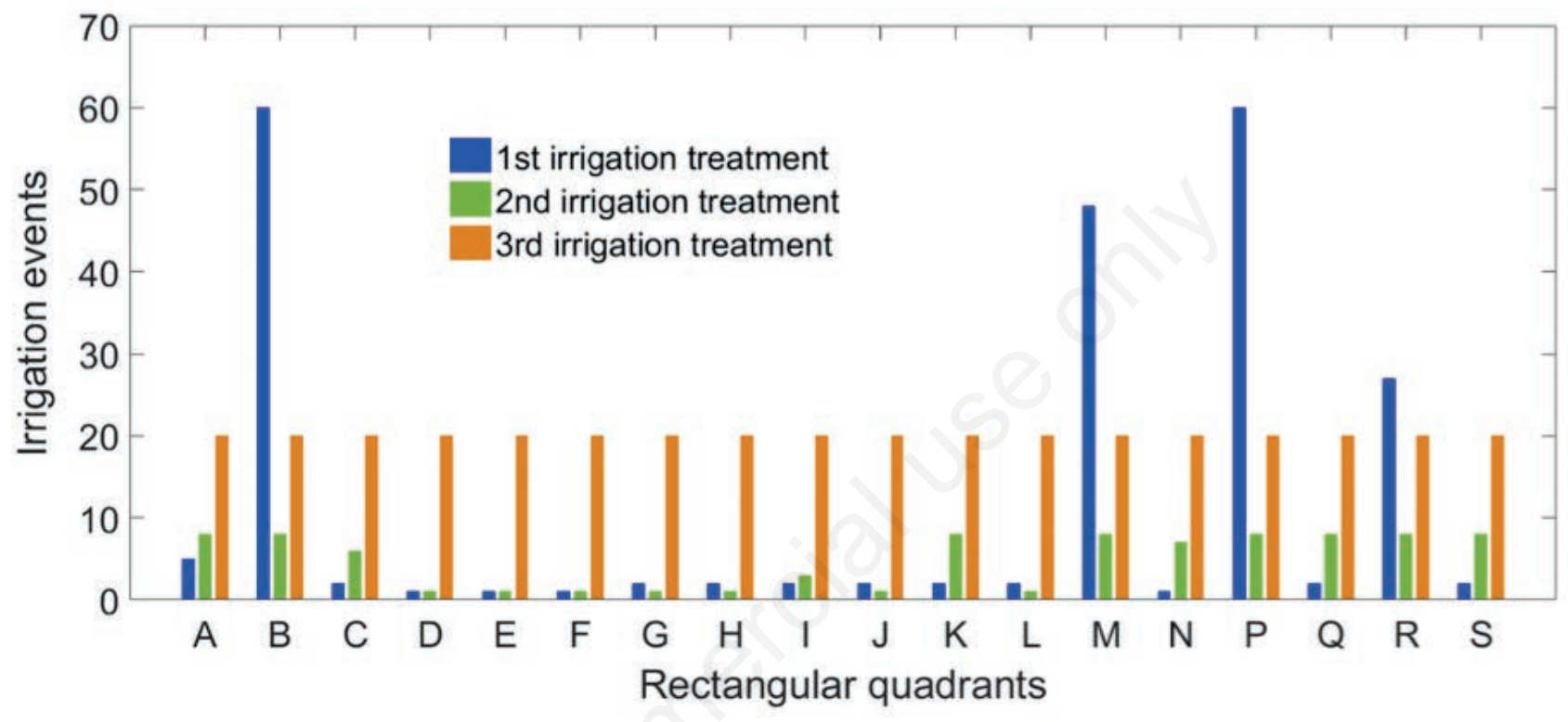

Figure 4. Comparison of events that were performed by the manipulator between the three irrigation treatments for each quadrant.

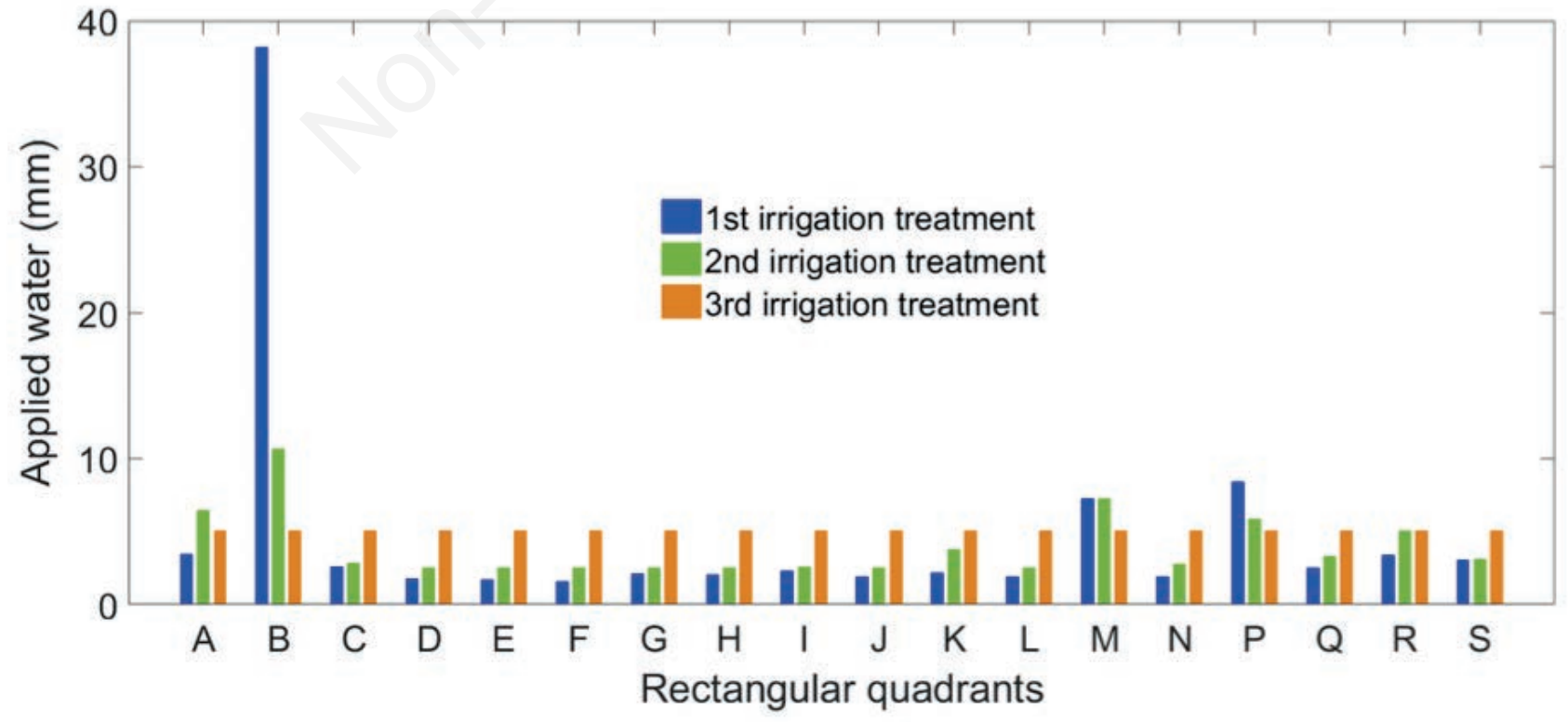

Figure 5. The amount of applied water by moving bridge manipulator at each quadrant of the soil tank, according to the observations provided by the sensor-based platform and the constraints imposed by irrigation treatments. 
In the following days, the irrigation water was applied by manipulator at variable rate.

In the third treatment, irrigation occurs by the manipulator with the same amount of water (uniform water application) at all quadrants every two days and regardless of the measured SWC by the sensor-based platform. After two months (29/10/2018$27 / 12 / 2018$ ) uniform water application, a total of $91 \mathrm{~mm}$ of water was applied to the area of the soil tank.

Box plots were used to compare the distributions of SWC for each quadrant of the soil tank during the three different irrigation treatments. By placing the box plots of soil water data sets in order, we can get information that includes shape, centre, spread, and any other features. Each boxplot (or box-and-whisker plot) is a graphic display of the five-number summary. The limits of each box display the median and the range of variation (the interquartile range, IQR) of soil water data set. The two whiskers display the minimum and maximum values in each data set. In addition, high maximum and low minimum outlying data points are displayed as red crosses, which show how far out the soil water data extend.

Box plot of Figure 6A compares the distributions of SWC between 18 quadrants of the soil tank during first irrigation treatment. At first glance all boxes seem to balance around refill point or to have higher SWC except the box of the quadrant B that shows the lower values of SWC. In addition, the box of quadrant G shows the highest values of SWC much greater than the field capacity. The upper position of the boxes for quadrants D, E, F, G, H, I, J, and $\mathrm{L}$ in comparison to the lower position of the rest boxes reveals that generally two areas are formed in the soil tank, one of which is wetter than the other. If we ignore the outliers, the variation in the more boxes is very short and similar, except the boxes for quadrants F, G, H, I, J, and Q whose interquartile range is larger. The limited interquartile range in the distributions of SWC indicates that the soil water conditions in the more quadrants of the soil tank stayed consistent during first irrigation treatment. Large outliers were identified in soil water data sets for quadrants $E, G, H$, I, J, K, L, R, and S.

Box plot comparing the distributions of SWC for the 18 quadrants of the soil tank during the second irrigation treatment is given in Figure 6B. The SWC results from the second treatment are slightly different than those obtained during the first irrigation treatment. The majority of boxes are laid between refill point and field capacity, except the boxes of quadrants A, B, M, P, and R that are lower than refill point. Six boxes in the plot have the position of the median in the middle creating distributions of SWC with symmetric shape. The distributions of SWC show wider interquartile range during the second irrigation treatment, even though the quadrants of the soil tank received smaller amounts of applied water by moving bridge manipulator.

Figure 6C displays box plot of SWC measured on 18 quadrants of the soil tank over the third irrigation treatment. Overall the boxes of the third irrigation treatment show SWC distributions significantly different from the first and second treatments. The median SWC is noticeably higher than the two previous irrigation treatments. The boxes also show wider interquartile range, pointing to larger variability of SWC. It is obvious that this is due to the uniform and periodic application of water over all quadrants. However, the periodic irrigation by moving bridge manipulator created more wet conditions within the tank.

A series of means values were generated from the daily SWC collected from the 18 quadrants of the soil tank during each irrigation treatment. Figure 7 shows a comparison of the time series of the daily mean SWC in the tank over 60 days. During the first irrigation treatment, the applied water in first day caused SWC to increase above the refill point. The time required for the SWC to reach the vicinity of the high value was 5 days. In the rest days, mean SWC ranged between 0.22 and $0.23 \mathrm{~m}^{3} \mathrm{~m}^{-3}$, which is in the middle between field capacity and refill point. This time series of the mean SWC is characterised by a stable course. The factor affecting the stable course was irrigation treatments' occurring only in quadrants whose SWC was below the refill point.

During the second irrigation treatment, the SWC initially was overshooting the refill point, and the time required for the daily mean SWC to reach the value of the refill point was 18 days. In the next several days it fluctuated around this point $\left(0.18 \mathrm{~m}^{3} \mathrm{~m}^{-3}\right)$ after different irrigation rates. This irrigation can be described as bangbang. The water was applied when the daily mean SWC was below the refill point, only in quadrants with actual SWC lower than that limit, and stopped when the daily mean soil water is above the refill point. Since the daily mean SWC crosses the refill point changing the status successively, the process is cycling continually, going from below refill point to above, and back below.

During the third irrigation treatment, the daily mean SWC in the soil tank increases progressively, initially with faster and then slower rates. After the $40^{\text {th }}$ day, when daily mean SWC reached the limit of field capacity, it stabilised around this limit despite continued uniform and periodic irrigation in all quadrants of the soil tank by moving bridge manipulator.

Attempts in the direction of automation in plants irrigation are done or are in progress by several research groups, and obviously irrigation systems have significantly changed during the last century or even during the last decade (Nemali and van Iersel, 2006). Under the title automated irrigation system, we describe a system continuously monitoring status of SWC and other parameters, and direct water to where it is needed. The control of SWC is done automatically through decisions taken by a computational system (Pedras et al., 2009). The automated irrigation system aims to gradually reduce and eliminate the human factor and can significantly reduce water usage, unnecessary seepage, and runoff (Shirgure, 2012).

The degree to which the task of irrigation is automated is referred to as levels of automation. Automation levels range from complete human control to complete computer control (Parasuraman et al., 2000). At the current time, irrigation systems are classified in four levels: amateur efforts of no automation in home gardens and pot flowers (level 0), time based systems that apply water in the necessary quantity at the right time (level 1), closed loop systems where the user defines the control strategy and the control system takes over the decision on when and how much water to apply (level 2), and full automated irrigation systems, where a user interface is completely unnecessary (level 3) (Agrawal and Singhal, 2015).

The design of the automated irrigation systems should take the scalability under account (Lozoya et al., 2015). The scalability is the additional cost to extend the automated irrigation system (after adding hardware) in order to improve its performance. For instance, let's concentrate to the SWC measurement and let's assume that we need a measurement per $0.5 \mathrm{~cm}$ in order to capture the soil water variability. A simple solution is to place one soil moisture sensor in each corner of a grid with $0.5 \times 0.5 \mathrm{~m}$ squares that covers the whole cultivated area. It is a high costly solution. In this case the scalability factor is quite high, since to double the cultivated area we need to also double the number of soil moisture sensors. An alternative solution is to use one soil moisture sensor that moves and gets the corresponding measurements (such as the sensor-based platform). In this case the scalability factor can be quite small, depending on the used moving system and its design. 
$\mathbf{A}$

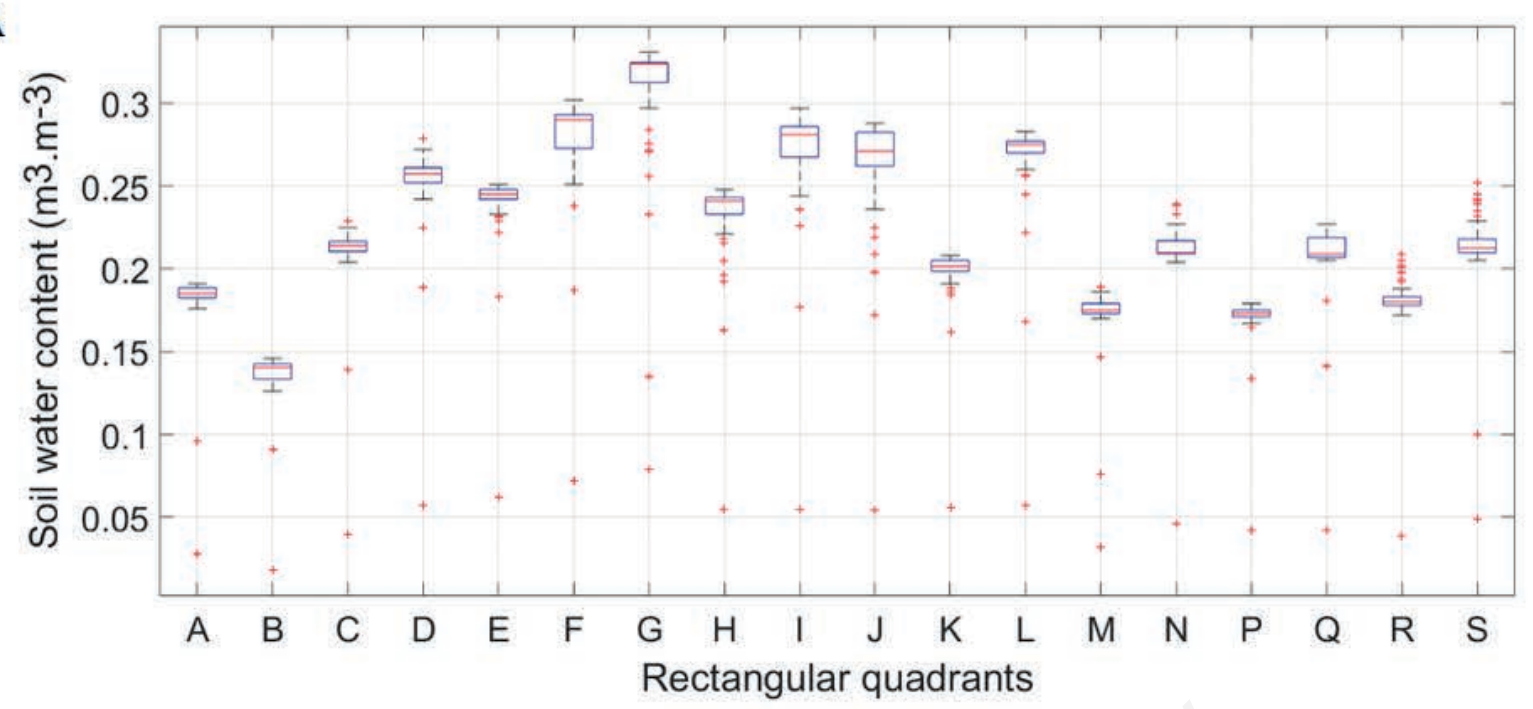

B

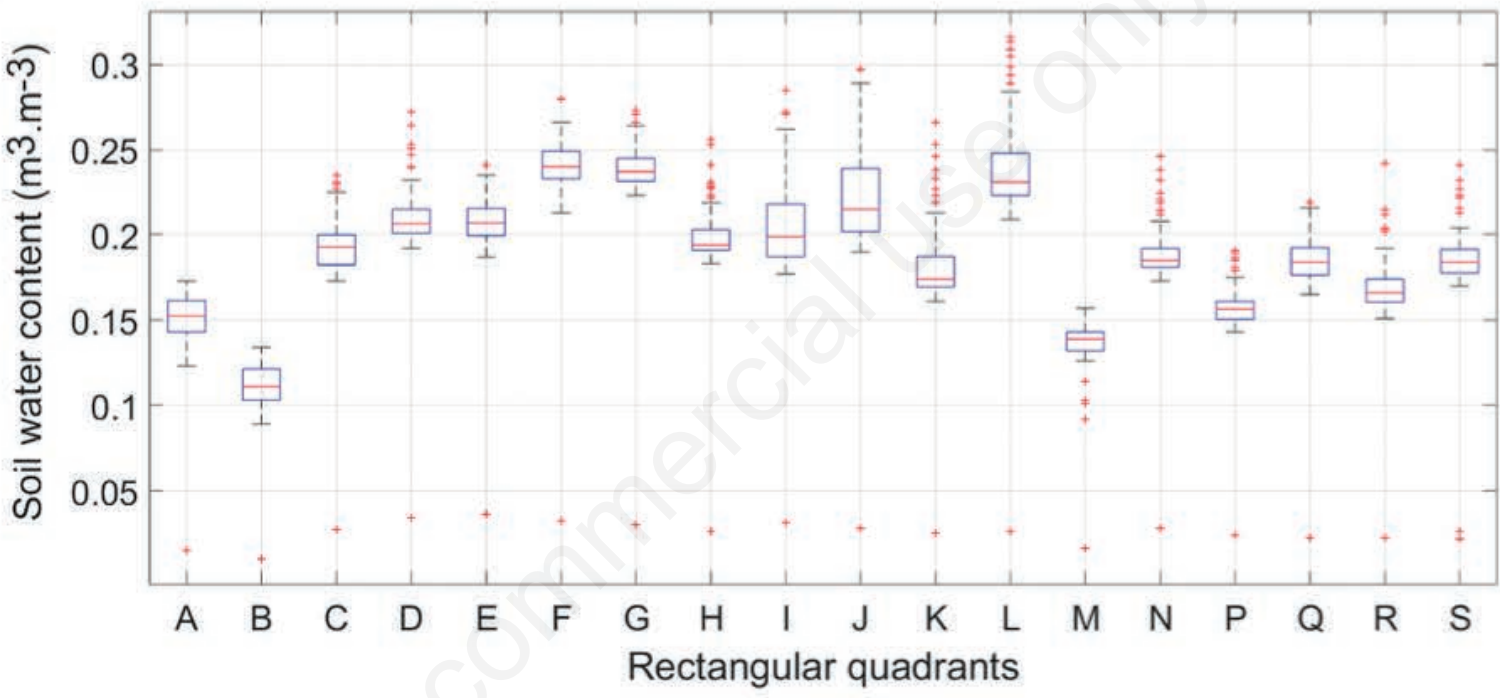

C

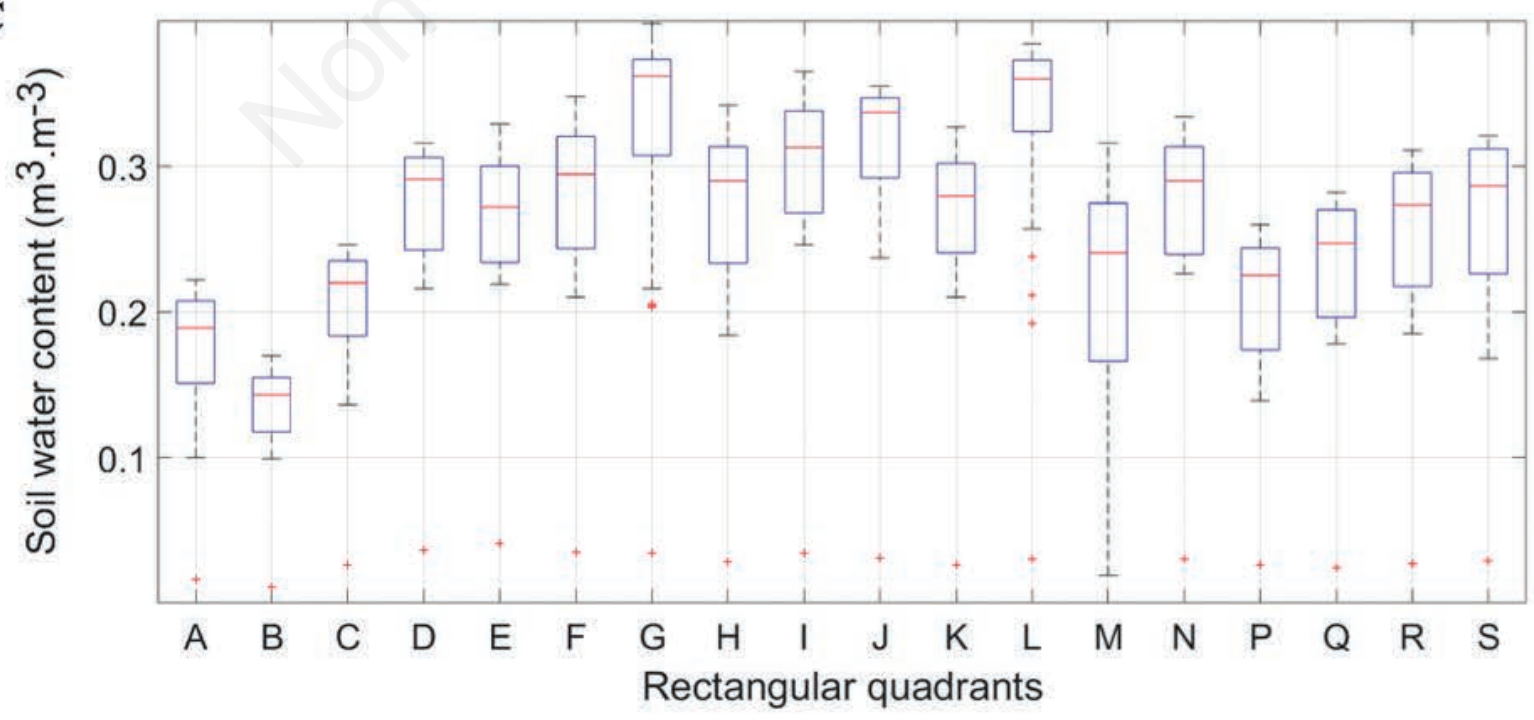

Figure 6. A) Box plot of soil water content (SWC) for quadrants of the tank during first irrigation treatment; B) box plot of SWC for quadrants of the tank during second irrigation treatment; C) box plot of SWC for quadrants of the tank during third irrigation treatment. 
The agricultural technology is developing rapidly, advancing robotics and automation technology. Agricultural robots automate slow, repetitive and dull tasks, allowing farmers to concentrate more on improving overall production yields. Some of the most common robots in agriculture are used for weed control, mowing, spraying, irrigation, etc.. In this contribution we addressed the problem of automatic controlling the SWC in urban gardening and agriculture. Especially, it is studied the relationship between water application under different treatments and soil water distribution in a soil tank. A robotic system was designed to manage irrigation water in the soil tank. The robot consisted of two major subsystems: a sensor-based platform and a moving bridge manipulator. Three-year irrigation experiments (2016-2018) were implemented to study the robotic system operation across three different treatments. The first two of the irrigation treatments were based on the application of different amounts to match water demands at the small scale of the soil tank, while in the third treatment the water was applied uniformly to the quadrants of the tank every two days. The irrigation robotic system was capable to monitor the SWC in real time, and perform watering the quadrants of the soil tank autonomously without any gardener intervention. Minimal irrigation events are a reason for increasing the manipulator performance, lower power consumption, reducing the operation cost, improved dexterity, improving safety, and introducing new functionalities (Moberg, 2010).

With the increasing demand for cultivating food crops in city open spaces, the market for irrigation robotic systems will grew substantially. Using manipulators to deliver exact quantities of water to precise locations in the soil surface can provide both improving the distribution and water use efficiency into urban gardening and agriculture and reduce total cost, which is beneficial for farmers and gardeners.

\section{Conclusions}

In this study, the implementation of a robotic system is presented which incorporates a moving bridge manipulator and a sensor-based platform. This robotic system used to control SWC of an experimental soil tank, which the total surface was divided by a raster into 18 equal quadrants. The performance of the irrigation robotic system was generally high. It responds satisfactorily to changes in soil water conditions. The presented robotic system can be used in different setups and does not require any qualified user.

A comparison of the results of the three different irrigation treatments shows that during the first irrigation treatment, the applied water was caused SWC to increase above the refill point and after 5 days the daily mean SWC was ranged between 0.22 and $0.23 \mathrm{~m}^{3} \mathrm{~m}^{-3}$. During the second irrigation treatment, the daily mean SWC initially was overshooting the refill point, and the next days it was fluctuated around this point (it was cycling continually, going from below refill point to above, and back below). Finally, during the third irrigation treatment, the daily mean SWC in the soil tank was increased progressively, initially with faster and then slower rates.

Spatial pattern of SWC within the experimental tank does not seem to be influenced significantly by the application of the three different irrigation treatments. This is not surprising because the SWC within the tank directly was affected by the soil physical properties, which remained undisturbed as the soil within the tank was not cultivated (zero tillage treatments).

The control of SWC could potentially increase yields by producing a more uniform environment for plant growth. The results indicate that feasibility of precision irrigation depends on soil water monitoring. Precision irrigation involves water application in optimum amounts. To secure the efficient use of water in urban gardening and agriculture, farmers and gardeners must adopt irrigation technologies based on robotic manipulators and soil water measuring instruments.

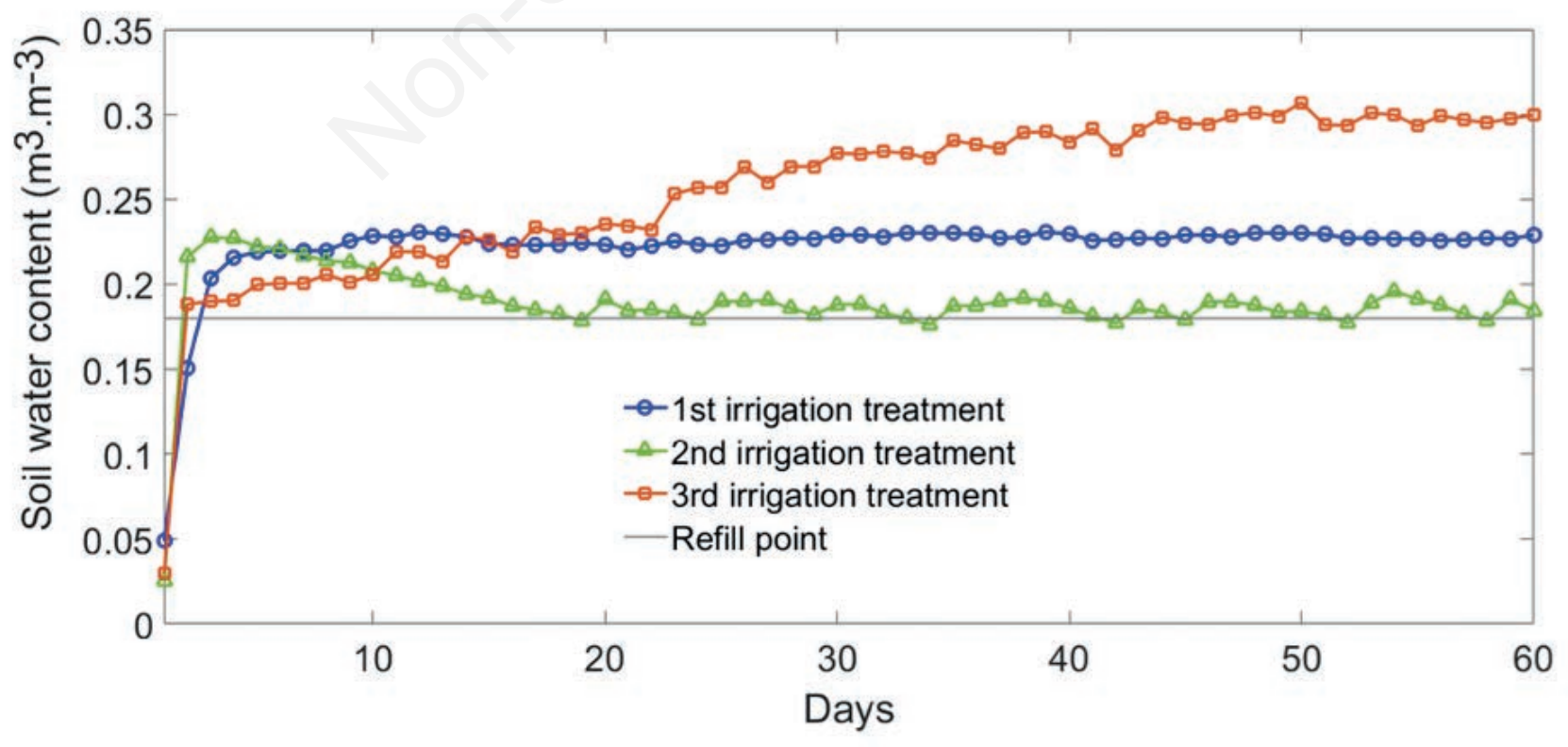

Figure 7. Time series of daily mean soil water content (SWC) in the soil tank over different irrigation treatments. 


\section{References}

Agostini A., Alenyà G., Fischbach A., Scharr H., Wörgötter F., Torras C. 2017. A cognitive architecture for automatic gardening. Comput. Electron. Agric. 138:69-79.

Agrawal N., Singhal S. 2015. Smart drip irrigation system using Raspberry pi and Arduino. International Conference on Computing, Communication and Automation (ICCCA2015), 928-932.

Aronson R.L. 2014. Farmbot: humanity's open-source automated precision farming machine. Tech. Farmbot https:/farmbot.io/.

Cofie O., Veenhuizen R. 2008. Sustainable use of water in urban agriculture. Agric. Mag. 20: 3-6.

Correll N., Arechiga N., Bolger A., Bollini M., Charrow B., Clayton A., Dominguez F., Donahue K., Dyar S., Johnson L., Liu H., Patrikalakis A., Robertson T., Smith J., Soltero D., Tanner M., White L., Rus D. 2009. Building a distributed robot garden. In Proc. IEEE/RSJ Int. Conf. Intell. Robots Syst., St. Louis, MO, 1509-1516.

Dhakal R.S., Syme G., Andre E., Sabato C. 2015. Sustainable Water Management for Urban Agriculture, Gardens and Public Open Space Irrigation: A Case Study in Perth. Agric. Sci. 6:676-685.

Ernwein M. 2014. Framing urban gardening and agriculture: On space, scale and the public. Geoforum 56:77-86.

Goldberg, K. 2000. The Robot in the garden-telerobotics and telepistemology in the age of the internet. Cambridge, MA: MIT Press.

Gravalos I., Gialamas Th., Kateris D., Xyradakis P., Tsiropoulos Z., Ralli M., 2007. A control system to achieve optimum soil water conditions for plant growth. $3^{\text {rd }}$ International Conference TAE2007, Prague, Czech Republic.

Gravalos I., Moshou D., Loutridis S., Gialamas T., Kateris D., Tsiropoulos Z., Xyradakis P., 2012. Design of a pipeline sensor-based platform for soil water content monitoring. Biosyst. Eng. 113:1-10.

Gravalos I., Moshou D., Loutridis S., Gialamas T., Kateris D., Bompolas E., Tsiropoulos Z., Xyradakis P., Fountas S. 2013. $2 \mathrm{D}$ and $3 \mathrm{D}$ soil moisture imaging using a sensor-based platform moving inside a subsurface network of pipes. J. Hydrol. 499:146-153.

Gravalos I., Loutridis S., Gialamas T., Kateris D., Xyradakis P., Tsiropoulos Z. 2017. Dynamic behaviour of an in-pipe sensorbased platform for soil water monitoring. Comput. Electron. Agric. 134:11-18.

Groves S.J., Rose S.C. 2004. Calibration equations for Diviner 2000 capacitance measurements of volumetric soil water content of six soils. Soil Use Manag. 20:96-97.
Hanks R.J., Ashcroft G.L. 1980. Applied soil physics. SpringerVerlag, New York.

Klute, A. 1986. Water retention: Laboratory methods. In A. Klute (ed.) Methods of soil analysis, Part $1,2^{\text {nd }}$ ed. Agron. Monogr. 9 ASA and SSSA, Madison, WI.

Kohanbash D., Valada A., Kantor G.F. 2011. Wireless sensor networks and actionable modelling for intelligent irrigation. Amer. Soc. Agr. Biol. Eng. Paper No. 1111174.

Lozoya C., Mendoza C., Torres V., Gallegos S., Terán R. 2015. A scalable design approach for a precision irrigation data acquisition system. ASABE Paper No. 152189487. St. Joseph, Mich.

Moberg S. 2010.Modeling and Control of Flexible Manipulators. $\mathrm{PhD}$ dissertation, Linköping University Electronic Press.

Nemali K.S., van Iersel M.W. 2006. An automated system for controlling drought stress and irrigation in potted plants. Sci. Hortic. 110:292-297.

Nolasco J. 2011. Sustainable water management for urban agriculture: Planting Justice. Oakland, CA: Working Paper Pacific Institute.

Opitz I., Berges R., Pior A., Krikser, T., 2016. Contributing to food security in urban areas: differences between urban agriculture and peri-urban agriculture in the Global North. Agric. Hum. Values 33:341-358.

Orsini F., Kahane R., Nono-Womdim R., Gianquinto G., 2013. Urban agriculture in the developing world: a review. Agron. Sustain. Dev. 33(4):695-720.

Parasuraman R., Sheridan T.B., Wickens C.D. 2000. A model for types and levels of human interaction with automation. IEEE Transactions on Systems, Man, and Cybernetics-Part A: Systems and Humans 30(3):286-297.

Pedras C.M.G., Pereira L.S., Gonçalves J.M. 2009. MIRRIG: A decision support system for design and evaluation of microirrigation systems. Agric. Water Manag. 96:691-701.

Sentek Pty Ltd. 2007. Diviner 2000 User Guide Version 1.4. South Australia, Stepney.

Sidblad S. 2000. Swedish perspectives of allotment and community gardening. Acta Hort. (ISHS) 523:151-160.

Shirgure P.S. 2012. Micro-irrigation systems, automation and fertigation in citrus. Scientific Journal of Review 1(5):156-169.

Sun Y., Zhou H., Qin Y., Lammers P.S., Berg A., Deng H., Cai X., Wang D., Jones S.B. 2014. Horizontal monitoring of soil water content using a novel automated and mobile electromagnetic access-tube sensor. J. Hydrol. 516:50-55.

Taylor S.A., Ashcroft G.L. 1972. Physical edaphology: The physics of irrigation and non-irrigated soils. Freeman, San Francisco. 